\title{
TARIKAN KENDARAAN PADA KAMPUS UNIVERSITAS BATANGHARI
}

\author{
Ishak *), Rio Samphana **) \\ *) Staff Pengajar Fakultas Teknik \\ **) Mahasiswa Program Studi Teknik Sipil
}

\begin{abstract}
University Batanghari previously was a development of the High School of Teacher Training and Education. A strong desire from the public to the availability of higher education institutions in a wider spectrum, then on 1 November 1985 was officially stood Batanghari University. Currently the University of Batanghari parenting 5 faculties with 16 programs of study, comprising 13 courses Strata (S-1), 2 Program Level Education Strata two (S-2) and 1 Study Program Level Education Diploma three (D-3 ). Until the year 2013/2014 the number of graduates (Alumni) until graduation 35 in June 2014 as many as 8771 people. Students will create attraction and great traffic generation.

The results of research in the field showed that for the expenditures of the students had no significant effect on the vehicle pull to the campus of the University Batang (sig> 0.05), while the frequency factor visit new students to campus gained significant effect equation $Y=2.78+0.85 X 2$ and also the distance factor to the equation $Y=1.26+1.32 \times 2 X 3$
\end{abstract}

\section{Intisari}

Universitas Batanghari merupakan pengembangan dari Sekolah Tinggi Keguruan dan Ilmu Pendidikan. Adanya keinginan yang kuat dari masyarakat agar tersedianya institusi pendidikan tinggi dalam spektrum yang lebih luas, maka pada tanggal 1 November 1985 secara resmi berdirilah Universitas Batanghari. Saat ini Universitas Batanghari mengasuh 5 Fakultas dengan 16 Program studi, yang terdiri 13 program studi jenjang Strata satu (S-1), 2 Program Studi jenjang Pendidikan Strata dua (S-2) dan 1 Program studi jenjang Pendidikan Diploma tiga (D-3). Sampai dengan tahun 2013/2014 jumlah lulusan (alumni) sampai wisuda 35 pada bulan Juni 2014 sebanyak 8.771 orang. Mahasiswa akan menimbulkan tarikan dan bangkitan lalulintas yang besar.

Hasil penelitian di lapangan menunjukan bahwa untuk biaya pengeluaran dari mahasiswa tidak berpengaruh signifikan untuk tarikan kendaraan ke kampus Universitas Batanghari (sig > 0,05) sedangkan faktor frekuensi kunjungan mahasiswa baru ke kampus berpengaruh signifikan didapat persamaannya $\mathrm{Y}=$ $2,78+0,85 \mathrm{X}_{2}$ dan juga faktor jarak yang ditempuh dengan persamaan $\mathrm{Y}=1,26$ $\mathrm{X}_{2}+1,32 \mathrm{X}_{3}$

Kata kunci : Tarikan, Bangkitan, Lalulintas

PENDAHULUAN

TARIKAN KENDARAAN PADA KAMPUS UNIVERSITAS BATANGHARI 
Catatan sejarah menunjukan bahwa Universitas Batanghari merupakan pengembangan dari Sekolah Tinggi Keguruan dan Ilmu Pendidikan. Atas keinginan yang kuat dari masyarakat agar tersedianya institusi pendidikan tinggi dalam spektrum yang lebih luas, maka pada tanggal 1 November 1985 secara resmi berdirilah Universitas Batanghari. Saat ini Universitas Batanghari mengasuh 5 Fakultas dengan 16 Program studi, yang terdiri 13 program studi jenjang Strata satu (S-1), 2 Program Studi jenjang Pendidikan Strata dua (S-2) dan 1 Program studi jenjang Pendidikan Diploma tiga (D-3). Sampai dengan tahun 2013/2014 jumlah lulusan (alumni) sampai wisuda 35 pada bulan Juni 2014 sebanyak 8.771 orang.

Perkembangan Mahasiswa Universitas Batanghari 5 tahun terakhir dari tiaptiap fakultas dapat dilihat tabel dan grafik dibawah ini :

Tabel 1.1. Jumlah Mahasiswa, Dosen dan Karyawan Universitas Batanghari 5 Tahun Terakhir

\begin{tabular}{c|c|c|c|c|c|c|c|c|c|c|c|}
\hline \multirow{2}{*}{ No } & \multirow{2}{*}{$\begin{array}{c}\text { Tahun } \\
\text { Akademik }\end{array}$} & \multicolumn{4}{|c|}{ Jumlah Mahasiswa } & \multicolumn{5}{c|}{ Presentase Pertumbuhan (\%) } \\
\cline { 3 - 14 } & & FKIP & Ekonomi & Hukum & Teknik & Pertanian & FKIP & Ekonom & Hukum & Teknik & Pertanian \\
\hline 1 & 2010 & 1739 & 1072 & 1418 & 586 & 237 & 0.00 & 0.00 & 0.00 & 0.00 & 0.00 \\
\hline 2 & 2011 & 1763 & 1068 & 1346 & 547 & 259 & 1.38 & -0.37 & -5.08 & -6.66 & 9.28 \\
\hline 3 & 2012 & 1588 & 1061 & 1274 & 586 & 270 & -8.68 & -1.03 & -10.16 & 0.00 & 13.92 \\
\hline 4 & 2013 & 1364 & 1154 & 1197 & 608 & 261 & -21.56 & 7.65 & -15.59 & 3.75 & 10.13 \\
\hline 5 & 2014 & 1173 & 1389 & 1330 & 655 & 287 & -32.55 & 29.57 & -6.21 & 11.77 & 21.10 \\
\hline
\end{tabular}

Sumber : (Biro Administrasi Akademik Kemahasiswaan) BAAK, Universitas Batanghari, (2015)

Tarikan pergerakan adalah jumlah pergerakan yang tertarik menuju ke suatu zona atau tata guna lahan dan jumlah pergerakan yang tertarik. pergerakan yang berasal dari suatu zona pergerakan yang menuju suatu zona (Tamin, 2000)

Bangkitan Perjalanan dapat diartikan sebagai banyaknya perjalanan atau pergerakan atau lalu-lintas yang dibangkitkan oleh suatu zona (kawasan) per satuan waktu (per detik, menit, jam, hari, minggu, dan seterusnya). Dari

\begin{tabular}{|c|c|c|c|c|c|c|c|c|c|c|c|}
\hline \multirow{2}{*}{ No } & \multirow{2}{*}{$\begin{array}{c}\text { Tahun } \\
\text { Akedemik }\end{array}$} & \multicolumn{5}{|c|}{ Jumlah Dosen } & \multicolumn{5}{|c|}{ Jumlah Karyawan } \\
\hline & & FKIP & Ekonomi & Hukum & Teknik & Pertanian & FKIP & Ekonomi & Hukum & Teknik & Pertanian \\
\hline 1 & 2010 & 27 & 27 & 31 & 23 & 18 & 8 & $\begin{array}{r}6 \\
\end{array}$ & 8 & 4 & 2 \\
\hline 2 & 2011 & 46 & 29 & 33 & 30 & 20 & 9 & 8 & 13 & 9 & 6 \\
\hline 3 & 2012 & 45 & 29 & 33 & 30 & 20 & 10 & 8 & 13 & 9 & 6 \\
\hline 4 & 2013 & 45 & 29 & 33 & 30 & 20 & 10 & 8 & 13 & 9 & 6 \\
\hline 5 & 2014 & 45 & 29 & 33 & 30 & 20 & 10 & 8 & 13 & 9 & 6 \\
\hline
\end{tabular}

pengertian tersebut, maka bangkitan perjalanan merupakan tahap pemodelan transportasi yang bertugas untuk memperkirakan dan meramalkan jumlah (banyaknya) perjalanan yang berasal (meninggalkan) dari suatu zona atau (menuju) ke suatu zona/kawasan/petak lahan pada masa yang akan datang (tahun rencana) per satuan waktu. (Fidel Miro, 2004) 
Sistem pergerakan sangat mempengaruhi tata guna lahan. Perbaikan akses transportasi akan meningkatkan atraksi/tarikan kegiatan dan berkembangnya gunalahan kota. Sistem transportasi yang baik akan menjamin pula efektivitas pergerakan antar fungsi kegiatan di dalam kota itu sendiri. Sistem transportasiperkotaan terdiri dari berbagai aktivitas seperti bekerja, sekolah, olah raga, belanja dan bertamu yang berlangsung di atas sebidang tanah (rumah, sekolah, pertokoandan lain - lain). Potongan lahan ini biasa disebut tata guna lahan.

Perencanaan transportasi dapat didefinisikan sebagai suatu proses yangtujuannya mengembangkan sistem transportasi yang memungkinkan manusia dan barang bergerak dan berpindah tempat dengan aman dan murah.Tujuan perencanaan transportasi adalah meramalkan dan mengelola evolusi titik keseimbangan antara kebutuhan akan pergerakan dan dengan sistem prasarana transportasi sejalan dengan waktu sehingga kesejahteraan sosial dapat dimaksimumkan.(Tamin, 2000)

Konsep perencanan transportasi telah berkembang hingga saat ini, dan yang paling populer adalah Model Perencanaan Transportasi Empat Tahap. Model ini memiliki beberapa seri sub-model yang masing-masing harus dilakukan secara terpisah dan berurutan. Sub-model tersebut:

-. Aksesibilitas

-. Bangkitan dan Tarikan Pergerakan (Trip Generation),

-. Sebaran Pergerakan (Trip Distribution),

-. Pemilihan Moda,

-. Pemilihan Rute

-. Arus Lalulintas Dinamis

Bangkitan lalu lintas ini tergantung dari aspek tata guna lahan, transportasi dan arus lalu lintas dapat pula dipergunakan pendekatan secara kuantitatif. Untuk itu dapat dilakukan dengan penggunaan model matematik, yaitu suatu cara untuk mempresentasikan suatu realita dengan menyederhanakan permasalahan. Dengan menggunakan model ini maka kita dapat mengambil suatu pendekatan, asumsi/anggapan yang mendekati kenyataan. Sehingga model yang terjadi sudah barang tentu mempunyai suatu tingkat kesalahan tertentu.

Model Analisis Regresi adalah suatu model dalam pemodelan Trip Generation yang dilakukan sebagai usaha untuk mendapatkan hubungan linier antara jumlah pergerakan yang dibangkitkan atau tertarik oleh zona dari ciri sosioekonomi rata-rata dari rumah tangga pada setiap zona.

Ada 3 (tiga) pendekatan untuk analisa regresi :

a. Analisa Regresi Linier Sederhana

b. Analisis Regresi Linier Berganda (Multiple Linier Regression Analysis)

c. Analisis Regresi Non Linier 
Teknik analisa regresi adalah suatu teknik yang dapat digunakan untuk menghasilkan hubungan dalam bentuk numerik dan untuk melihat bagaimana variabel-variabel saling terkait. Pada analisa regresi linier sederhana, (Tamin, 2000) variabel/peubah yang digunakan dinyatakan dalam bentuk umum :

$\mathrm{Y}=\mathrm{a}+\mathrm{bx}$

Pers (1)

Dalam hal ini Metode Least Squares digunakan dalam proses regresi dimana garis linier didapat sehingga jumlah kuadrat terkecil dihasilkan.

Multiple Linier Regression Analysis adalah teknik statistik yang sering digunakan dalam memperkirakan Bangkitan-Pergerakan pada masa yang akan datang, dimana dua atau lebih variabel (faktor) bebas yang mempengaruhi jumlah pergerakan(Tamin, 2000). Teknik ini mengukur sampai sejauh mana pengaruh dari setiap faktor dan hubungannya dengan faktor lainnya.

Model umum bentuk ini adalah :

$\mathrm{Y}=\mathrm{a}+\mathrm{b} 1 \mathrm{X} 1+\mathrm{b} 2 \mathrm{X} 2+\ldots+\mathrm{bMXM}$

Pers (2)

Dimana :

$\mathrm{Y}=$ Variabel tidak bebas

$\mathrm{X} 1, \mathrm{XM}=\mathrm{m}$ variabel bebas

$\mathrm{b} 1, \mathrm{bM}=$ koefisien regresi

$\mathrm{a}=$ konstanta

Korelasi antara variabel tersebut dapat dinyatakan dengan suatu koefisien korelasi (r).Nilai $r$ berkisar antara -1 dan +1 . Tanda (+) dan tanda (-) dipakai untuk korelasi positif dan korelasi negatif. Koefisien korelasi sederhana (r) merupakan angka yang mengukur kekuatan hubungan antara 2 variabel (terikat dan bebas). Besarnya dapat dicari melalui paket program SPSS (Statical Program for Social Sccience) atau microstat dan secara manual. Secara Manual, r dapat dicari melalui perumusan berikut (Enns, 1985, Fidel Miro 2004) :

$\mathrm{r}=\frac{\sum \mathrm{xy}-(\Sigma \mathrm{x} . \mathrm{y}) / \mathrm{n}}{\sqrt{\sum \mathrm{x}^{2}-(\Sigma \mathrm{x})^{2} / \mathrm{n} \sqrt{\Sigma \mathrm{x}^{2}-(\Sigma \mathrm{x})^{2} / \mathrm{n}}}}$

Pers (3)

Di mana :

$\mathrm{r} \quad=$ koefisien korelasi sederhana

$\mathrm{x}$ dan $\mathrm{y}=$ variabel

$\mathrm{n} \quad=$ jumlah pengamatan

$\Sigma \quad=$ simbol penjumlahan

Koefisien determinasi sederhana $\left(\mathrm{r}^{2}\right)$ merupakan nilai yang dipergunakan untuk mengukur besar kecilnya sumbangan/konstribusi perubahan variabel bebas terhadap perubahan variabel terikat yang tengah kita amati (Fidel Miro, 2004). 
Dalam penelitian ini tahapan analisis korelasi merupakan tahapan terpenting didalam menentukan hubungan antara faktor-faktor yang berpengaruh pada pergerakan/transportasi.

Ada beberapa alat (perangkat lunak) yang digunakan untuk mengelola data hasil penelitian. Dalam hal ini digunakan program StatisticalProgram for Social Science (SPSS) Versi 20.0 for Windowsuntuk mendapatkan model regresi terbaik.

\section{METODOLOGI PENELITIAN}

Agar lebih jelas mengenai urutan metodologi penelitian ini,maka bagan alir program kerja seperti di bawah ini :

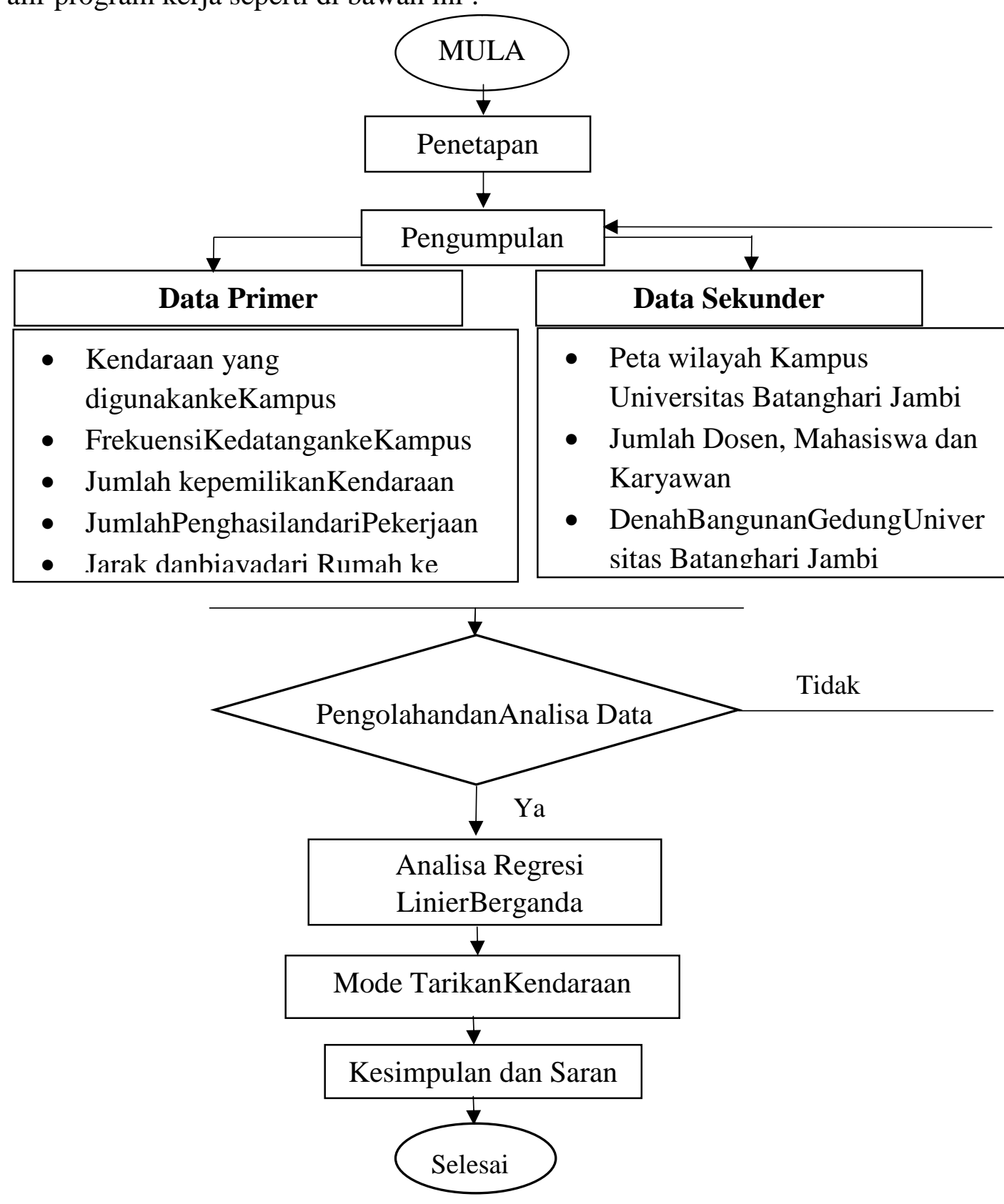


Gambar 1. Flowchart(Diagram Alir)Program Kerja

Sumber : Survei, 2015

\section{ANALISA DATA DAN PEMBAHASAN}

Tabel 1. Jumlah PilihanJeniskendaraankeUniversitasBatanghari

\begin{tabular}{|c|c|c|c|}
\hline No & ModaTransportasi & $\begin{array}{c}\text { Jumlah } \\
\text { Responden } \\
\text { (Mahasiswa) }\end{array}$ & $\begin{array}{c}\text { Persentase Jumlah } \\
\text { Responden (\%) }\end{array}$ \\
\hline 1 & Kendaraan Motor & 69 & 72 \\
\hline 2 & Kendaraan Mobil & 3 & 3 \\
\hline 3 & AngkutanUmum & 20 & 22 \\
\hline 4 & Tidak Ada/Jalan Kaki & 3 & 100 \\
\hline & Jumlah & 95 & \\
\hline
\end{tabular}

Sumber : Hasil Survei, 2015

Tabel 2. PengeluaranbiayakeKampusdalam 1 Minggu

\begin{tabular}{|c|c|c|c|}
\hline No & $\begin{array}{c}\text { Penghasilan Dalam } \\
\text { Satu Rumah (Rp) }\end{array}$ & $\begin{array}{c}\text { Jumlah } \\
\text { Responden } \\
\text { (Keluarga) }\end{array}$ & $\begin{array}{c}\text { Persentase Jumlah } \\
\text { Rospenden (\%) }\end{array}$ \\
\hline 1 & $>$ Rp1.000.000 & 46 & 48 \\
\hline 2 & Rp 100.000 - 500.000 & 39 & 41 \\
\hline 3 & $>\operatorname{Rp~500.000~}$ & 10 & 10 \\
\hline & Jumlah & 95 & 100 \\
\hline
\end{tabular}

Sumber : Hasil Survei, 2015

Tabel 3. JumlahFrekuensikunjungankeKampus

\begin{tabular}{|c|c|c|c|}
\hline No & Frekuensi & $\begin{array}{c}\text { Jumlah } \\
\text { Responden } \\
\text { (org) }\end{array}$ & $\begin{array}{c}\text { Persentase Jumlah } \\
\text { Responden (\%) }\end{array}$ \\
\hline 1 & $1-2$ Kali seminggu & 8 & 8 \\
\hline 2 & $3-4$ Kali seminggu & 39 & 41 \\
\hline 3 & $5-6$ Kali seminggu & 36 & 38 \\
\hline 4 & $>6$ Kali seminggu & 12 & 13 \\
\hline \multicolumn{2}{|c|}{ Jumlah } & 95 & 100 \\
\hline
\end{tabular}

Sumber : Hasil Survei, 2015 
Tabel 4. Jumlah Jarak yang ditempuh ke Kampus

\begin{tabular}{|c|c|c|c|}
\hline No & Jarak & $\begin{array}{c}\text { Jumlah } \\
\text { Responden } \\
\text { (org) }\end{array}$ & $\begin{array}{c}\text { Persentase Jumlah } \\
\text { Responden (\%) }\end{array}$ \\
\hline 1 & $1-5 \mathrm{~km}$ & 27 & 28 \\
\hline 2 & $5-10 \mathrm{~km}$ & 30 & 32 \\
\hline 3 & $10-20 \mathrm{~km}$ & 20 & 21 \\
\hline 4 & $>20 \mathrm{~km}$ & 18 & 19 \\
\hline & Jumlah & 95 & 100 \\
\hline
\end{tabular}

Sumber : Hasil Survei, 2015

\section{Aplikasi Metoda}

Data yang diperoleh dari questioner kemudian diolah dengan menggunakan software SPSSversi 20, dimanafaktorvariabelyang ditentukan antara lain:
a) Variabel terikat (Y) adalahModaTransportasi (MoTran)
b) Variabel bebas berturut-turut adalah:
- BiayaPengeluaran (BiPeng)
- Frekuensikekampus (FREK),dan
- Jarakkekampus (JRK)

\section{Tabel 5. Tabelhasil regresiFaktorBiayaPengeluaran}

\begin{tabular}{|l|r|c|c|c|}
\hline \multirow{2}{*}{ Variabel } & \multicolumn{4}{|c|}{ Regresi Linier } \\
\cline { 2 - 3 } & $\begin{array}{r}\text { Koef. } \\
\text { Regresi }\end{array}$ & $\mathrm{R}$ & $\mathrm{R}^{2}$ & $\begin{array}{c}\text { Signifikan } \\
\text { (Sig) }\end{array}$ \\
\hline Konstanta & -1.74 & & & 0.33 \\
\hline X1 & 1.08 & \multirow{2}{*}{0.996} & 0.993 & 0.11 \\
\hline X2 & 0.77 & & & 0.07 \\
\hline X3 & 0.00 & & & 1.00 \\
\hline
\end{tabular}

Sumber : Pengolahan data dengan SPSS, 2015

\section{a) PengaruhFrekuensikunjunganterhadapModatransportasi}

Untukhasilregresifaktorfrekuensikunjungan,

variabelterikatnyaadalahModatransportasi

$(\mathrm{Y})$

Sedangkanvariabelbebasnyaadalahpilihanjawabandarifaktorfrekuensikunjungan, antara lain:

- Frekuensikunjungankekampus 1 - 2 kali seminggu(X1)Dengan

- Frekuensikunjungankekampus 3 - 4 kali seminggu (X2)

- Frekuensikunjungankekampus 5 - 6 kali seminggu (X3)

- Frekuensikunjungankekampuslebihdari 6 kali seminggu (X4)

Dimanadenganmenggunakanaplikasi SPSS

versi 20,makadiperolehhasilregresisepertidibawahini : 
Tabel 6. Tabel hasil regresifaktorFrekuensikunjungan

\begin{tabular}{|l|r|r|r|r|}
\hline \multirow{2}{*}{ Variabel } & \multicolumn{3}{|c|}{ Regresi Linier } \\
\cline { 2 - 2 } & $\begin{array}{c}\text { Koef. } \\
\text { Regresi }\end{array}$ & $\mathrm{R}$ & $\mathrm{R}^{2}$ & $\begin{array}{c}\text { Signifikan } \\
\text { (Sig) }\end{array}$ \\
\hline Konstanta & -2.78 & & & 0.03 \\
\hline X1 & 1.40 & \multirow{4}{*}{0.999} & \multirow{2}{*}{0.998} & 0.25 \\
\hline X2 & 0.85 & 0.04 \\
\hline X3 & 1.06 & & & 0.11 \\
\hline X4 & 0.22 & & & 0.61 \\
\hline Sumber : Pengolahan data dengan SPSS, 2015 \\
\hline
\end{tabular}

Dimana :

X2 = Frekuensikunjungankekampus 3-4 kali seminggu

model regresilinier bergandanyaadalahsebagaiberikut :

$\mathrm{Y}=-2,78+0,85 \mathrm{X}_{2}$

$=-2,78+0,85(39)$

$=35,93 \mathrm{atau} 36 \%$

Dimana :

$\mathrm{Y}=$ Tarikan Perjalanan

$\mathrm{X}_{2}=$ Frekuensikunjungankekampus $3-4$ kali seminggu

\section{b) PengaruhJarakkekampusterhadapModatransportasi}

UntukhasilregresifaktorJarak yang ditempuhkekampus, variabelterikatnyaadalahModatransportasi

(Y),

Sedangkanvariabelbebasnyaadalahpilihanjawabandarifaktorjarakkekampus, antara lain:

- Jarakkekampus 1 - $10 \mathrm{~km}(\mathrm{X} 1)$

- FreJarakkekampus 10 - $20 \mathrm{~km}(\mathrm{X} 2)$

- Jarakkekampus 20 - 30 km (X3)

- Jarakkekampus> $30 \mathrm{~km}(\mathrm{X} 4)$

Dimanadenganmenggunakan SPSS versi 20, hasilregresi linierdenganfaktorjarakkekampusbisadilihatpadatabelberikutini:

Tabel 7. Tabel hasil regresifaktorJarakkekampus

\begin{tabular}{|l|r|c|c|r|}
\hline \multirow{2}{*}{ Variabel } & \multicolumn{4}{|c|}{ Regresi Linier } \\
\cline { 2 - 2 } & $\begin{array}{r}\text { Koef. } \\
\text { Regresi }\end{array}$ & $\mathrm{R}$ & $\mathrm{R}^{2}$ & \multicolumn{1}{|c|}{$\begin{array}{c}\text { Signifikan } \\
\text { (Sig) }\end{array}$} \\
\hline Konstanta & -2.69 & & & 0.05 \\
\hline X1 & 0.60 & \multirow{2}{*}{1.00} & 1.00 & 0.05 \\
\hline X2 & 1.26 & & & 0.02 \\
\hline X3 & 1.35 & & & 0.03 \\
\hline
\end{tabular}




\begin{tabular}{l|r|r|}
$\mathrm{X} 4$ & 0.23 & 0.19 \\
\hline Sumber : Pengolahan data dengan SPSS, 2015
\end{tabular}

Dimana :

X2 = Jarakkekampus $10-20 \mathrm{~km}$

X3 = Jarakkekampus $20-30 \mathrm{~km}$

Dari tabeldiatas, makadiketahuikoefisiendeterminasijarak yang ditempuhterhadapmodatransportasibaikuntukpergerakankendaraankekampus $(1,00>0.50)$. SelainituJarak yang ditempuhkekampus $10-20 \mathrm{~km}$ dan $20-30 \mathrm{~km}$ berpengaruhsignifikanterhadapModatransportasi $(\mathrm{sig}<0,05)$. Maka model regresilinier bergandanyaadalahsebagaiberikut :

$$
\begin{aligned}
\mathrm{Y} & =1,26 \mathrm{X}_{2}+1.35 \mathrm{X}_{3} \\
& =1,26(30)+1.35(20) \\
& =64,80 \mathrm{atau} 64 \%
\end{aligned}
$$

Dimana :

$\mathrm{X}_{2} \quad=$ Jarakkekampus $10-20 \mathrm{~km}$

$\mathrm{X}_{3} \quad=$ Jarakkekampus $20-30 \mathrm{~km}$

\section{c) PengaruhsemuafaktorterhadapModatransportasi}

Untukhasilregresisemuafaktor yang

ada, variabelterikatnyaadalahModatransportasi (Y), SedangkanvariabelbebasnyaAntara lain:

- Biayapengeluaran (X1)

- Frekuensikunjungankekampus (X2)

- Jarak yang tempuhkekampus (X3)

\begin{tabular}{|c|c|c|c|c|}
\hline \multirow[b]{2}{*}{ Variabel } & \multicolumn{4}{|c|}{ Regresi Linier } \\
\hline & $\begin{array}{l}\text { Koef. } \\
\text { Regresi }\end{array}$ & $\mathrm{R}$ & $\mathrm{R}^{2}$ & $\begin{array}{l}\text { Signifikan } \\
\text { (Sig) }\end{array}$ \\
\hline Konstanta & 0.96 & \multirow{4}{*}{0.38} & \multirow{4}{*}{0.15} & 0.01 \\
\hline $\mathrm{X} 1$ & 0.02 & & & 0.88 \\
\hline $\mathrm{X} 2$ & 0.34 & & & 0.00 \\
\hline X3 & -0.16 & & & 0.05 \\
\hline
\end{tabular}

Untukhasiltabelnyadapatdilihatpadatabel di bawahini :

Tabel8.TabelregresisemuafaktorterhadapModatransportasi

Dimana :

X2 = Frekuensikunjunganmahasiswabarukekampus

Dari

makadiketahuikoefisiendeterminasisemuafaktorterhadapmodal

transportasikurangbaikuntukpergerakankendaraankekampus $(0,15<0.50)$.

Selainitu, diperolehvariabelbebasfrekuensikunjunganmahasiswabarukekampus

paling berpengaruhsignifikanterhadaptarikankendaraankekampusUniversitas 
Batanghari,yaitutidakmelewatibatassignifikan(Sig <0,05). Dari hasildiatas, Maka model regresilinier bergandanyaadalahsebagaiberikut :

$\mathrm{Y}=0,96+0,34 \mathrm{X}_{2}$

$=0,96+0,34(95)$

$=33,26$ atau $33 \%$

Dimana :

$\mathrm{Y} \quad=$ Tarikan Perjalanan

$\mathrm{X}_{2} \quad=$ Frekuensikunjungankekampus

$\mathrm{X}_{3} \quad=$ Jarak yang ditempuhkekampus

\section{PENUTUP}

\section{KESIMPULAN}

Berdasarkan analisa dapat diambil kesimpulan :

1. Biaya pengeluaran tidak berpengaruh signifikan untuk tarikan kendaraan ke kampus Universitas Batanghari (sig > 0,05)

2. Faktor frekuensi kunjungan mahasiswa baru ke kampus berpengaruh signifikan untuk tarikan ke kampus Universitas Batanghari, persamaan regresi sebagai berikut:

$$
\mathrm{Y}=2,78+0,85 \mathrm{X}_{2}
$$

3. Faktor jarak yang ditempuh didapat persamaan regresi

$$
\mathrm{Y}=1,26 \mathrm{X}_{2}+1,32 \mathrm{X}_{3}
$$

\section{SARAN}

1. Pada saat survey sebaiknya dilengkapi dengan alat penghitung digital dan kamera untuk merekam kejadian pada saat melakukan survey

2. Perlu kehati-hatian dalam memasukan data pada pengolahan statistik 


\section{DAFTAR PUSTAKA}

Miro Fidel. (2005). Perencanaan Transportasi untuk Mahasiswa, Perencana, dan Praktisi. Erlangga.

Rumanga Andri Asto. (2014). Analisis Model Bangkitan Kendaraan Pada Sekolah Swasta di Zona Pinggiran Kota di Kota Makassar. Makassar : Universitas Hasanuddin.

Tamin Ofyar Z. (2000). Perencanaan dan Pemodelan Transportasi. Bandung : ITB.

Yuliani. (2004). Analisi Model Tarikan Perjalanan Pada Kawasan Pendidikan di Cengklik Surakarta. Surakarta : Universitas Sebelas Maret 